\title{
Research on the Change Path of Editing and Publishing under the "Internet +" Horizon
}

\author{
Chunbo Qu
}

Northeast Normal University Press, Changchun, China.

\begin{abstract}
With the rise and development of China's Internet economy, the "Internet +" era has entered various fields and industries, and has also triggered industry changes. It has changed the development of the industry and injected new impetus into editing and publishing. The editing and publishing industry should understand the current situation, adjust the development ideas and strategies in a timely manner, and achieve the sustainable and healthy development in a new era. Starting from the background of "Internet +", this paper analyzes the specific performance of editing and publishing under the "Internet +" horizon, and proposes the main path of editing and publishing changes, which is of great significance to the current reform of editing and publishing industry.
\end{abstract}

Keywords: Internet +, editing and publishing, change path, big data.

\section{Introduction}

Under the influence of the Internet, China's various industries have more space for development and face more challenges. The Internet has threatened traditional industries in terms of thinking, strategy, business model, marketing model, product model, and supply chain pattern. The traditional industry has faced a dilemma of transformation or non-transformation. At present, China is carrying out the supply-side reforms, tries to optimize the economic structure, promote the implementation of "Internet +" strategy, drive the integration of mobile Internet, cloud computing, big data, Internet of things, and other industries, and accelerate the development of e-commerce, industrial Internet, and Internet finance. The traditional industry has ushered in new development opportunities.

\section{Definition and Characteristics of "Internet +"}

\subsection{Definition of "Internet +"}

It is only half a century since the birth of the Internet. The rapid development and wide range of coverage of the Internet are unmatched by other science and technology. As an important symbol of the third industrial revolution, the Internet has influenced and promoted the development and progress of the entire era. The "Internet +", as a new format of Internet development, will surely become a new force to promote the development of the times. Besides, the "Internet + " has provided a broad network platform for social and economic development, and become an important propellants and accelerators for the healthy and sustainable development of the industry.

\subsection{Characteristics of "Internet +"}

The first is cross-border integration. The core of "Internet + " lies in the transformation of the traditional format, and the meaning of "+" is cross-border. It is a breakthrough reform of the traditional format. At present, the industry faces bottlenecks in development. How to handle the current difficulties and deal with the bottlenecks is an urgent for us. We must dare to carry out the cross-border upgrades of traditional industries, which mean not only the upgrades of product development and research, but also the upgrades of development model, marketing, and service.

The second is innovation drive. The development bottleneck currently encountered by traditional industries is due to the fact that the Chinese industry has long relied on extensive driving growth, which has been difficult to sustain in the development of modern economy. To achieve the industrial breakthroughs and development, the industry must turn from the traditional extensive drive to the modern innovation drive. In the Internet environment, we must develop the Internet thinking, pursue for self-transformation, conduct breakthrough innovations, and achieve sustainable development. 
The third is structure reshaping. The rapid development of globalization and informatization is gradually changing the social structure and economic pattern. The traditional structure has become unsuitable and even hindered the development and progress of the social economy. Under such a historical background, with the times changing, the social structure upgrading, and the economic structure adjusting, the industry must adapt to these changes and achieve the transformation and upgrading in time. Otherwise, the industry will be lost in the historical trend.

The fourth is the open ecology. The "Internet + " is open. The traditional format has been gradually changed by the "Internet +". It introduces a more open ecological environment and provides an open development platform, connecting the isolated islands and triggering new powers in the process of innovations. The vitality of development will give innovative entrepreneurs more opportunities to develop and provide a broader platform for innovation and entrepreneurship.

The fifth is to connect everything. With the rapid development of the economy and society, the concept of the traditional global village has gradually escalated. It is foreseeable that the future development of the economy and society will be more interconnected. In the context of the Internet, The goal of "Internet +" development involves how to achieve the differentiated connections, how to integrate and exert social resources, how all traditional contents can be connected to the Internet platform, and achieve a new integration and development of social economy.

\section{The New Normal for Editing and Publishing under the "Internet +" Horizon}

Before the appearance of the "Internet +", the traditional industries have an urgent need to be upgraded and a large number of "Internet +" models are gaining momentum to seize the market of traditional industries. Although currently the "Internet + " is still in an initial stage to certain extent, and even be taken as nothing real but a hot topic, the industries that are deeply rooted in the Internet are more active and can precisely capture the changes of the "Internet +", compared with the passive situation of the traditional industry. They are capable of integrating more fields and constantly expanding its ecology. The traditional industries' exploration on the Internet is mainly focusing on the Internet marketing. Many traditional Internet industries use the "B2B, B2C" e-commerce platform to expand online marketing. Or, some industries choose to disclose the information and advertising through the Internet in the process of development. Some traditional industries with strong strengths have built their own e-commerce platforms to engage in business, but few have succeeded. Contrary to the traditional industries, in the tide of innovation and entrepreneurship, emerging startups rooted in the Internet industry are deeply integrated with the Internet on business projects. They are in the form of "Internet + " at the beginning of their business, which make them face less pressure in the process of transformation and upgrading. Besides, they may enjoy a high possibility of success in transformation and upgrading. Specifically in the editing and publishing sector, the new normal is mainly reflected in the following aspects.

\subsection{Diversified Information Fusion}

With the rapid development of the era of big data, the intelligent software has gradually become popular. From a certain perspective, information technology is profoundly affecting all the elements of editing and publishing, regardless of the submission platform, publishing platform and communication channels. Information technology has played a significant role in it. For example, electronic textbooks are the products of the new era and have gradually matured and become a new type of publication. Electronic books can not only integrate multimedia and digitalization, realizing the interpersonal interaction, but also achieve perfect reading experience in both visual and auditory sense.

\subsection{Consumer Experience Upgrading}

In the context of the rapid development of technology, the product is updated faster and the number of products grows rapidly. People are inclined to focusing more on consumer experience. For example, the currently popular Apple series can win the favor of consumers because they can upgrade the 
consumer experience. The Apple series can not only meet the needs of consumers in terms of the product performance, but also improve the satisfaction of consumers when they actually use the products. Under the background of "Internet +", the consumer experience largely determines the consumer's loyalty to the product.

\subsection{The Trend of Cross-Border Is Obvious}

Different from the traditional industry layout, the trend of decentralization in the "Internet +" era is obvious. This development trend and behavioral performance are closely related to the degree of development of the Internet. The more the Internet develops, the more blurred the boundaries between industries. The speed of information flow is accelerating, especially in the context of the rapid development of smart phones and mobile Internet. The rapid and explosive development of various media has broken the specialization of editing and publishing, which promoted the cross-border development of the publishing industry.

\subsection{The Development of Artificial Intelligence}

The rapid development of artificial intelligence is the most important representative of the progress of science and technology during recent years. It can be said that the artificial intelligence is gradually coming. As a representative product of this era, new robots play an irreplaceable role in people's industrial production and daily life. As a result, the editing and publishing industry will also make great use of artificial intelligence to achieve intelligent development. New robots like writing robots have emerged. Unlike manual writing, these robots are more efficient and cost less to write. With the popularity of artificial intelligence, achieving the intelligent editing and publishing should be an important goal of reform.

\section{The Change Path of Editing and Publishing under the "Internet +" Horizon}

\subsection{Introduce the Internet Thinking and Emphasize the Service Spirit of Products}

In the "Internet +" era, the Internet is changing every industry. It has changed people's access to information and upgraded the traditional reading habits. When readers search for the books they want in a huge amount of information, it is not easy for the traditional editing mode to meet readers' needs due to the lack of guidance and discrimination. The development of paper books is getting worse. In order to achieve sustainable development and progress, the editing and publishing industry must adapt to the current format and actively introduce the Internet thinking, giving absolute priority to user experience. Only by thinking about the development of products from the perspective of users, can we understand the needs of users, adjust the business mode, continuously optimize the reading experience, and meet the individual needs of users. This is also an important inner force driving the development of editing and publishing under the new normal.

The service spirit of the product is not only reflected in the readers, but also in the content production, that is, to pay attention to the author resources of the publishing industry. The author resources are the magic weapon for determining the sustainable competition in the pay-for-knowledge field. In the era of pay-for-knowledge field, the competition for readers and authors is an important determinant of the editing and publishing companies' life and death.

\subsection{Develop a Reader Database to Implement Precise Marketing}

China is transforming from the information age to the data age. If an enterprise wants to maintain sustainable development in this context, it is very important to master the data analysis technology. By means of analyzing the industry data, companies can grasp the development trend of the industry timely, and further establish the development strategies. For the editing and publishing industry, developing a reader database is an extremely important action. The database includes not only the readers' reading interests and needs, but also their reading habits. With the data model, enterprises can strengthen data analysis and understand users' needs immediately. This is the most direct, real, 
and effective market information, which provides a more precise direction for editors and publishers to choose topics and publish books.

The establishment of a reader database also includes an open communication platform, which enables more accurate book marketing. Data can help enterprises achieve accurate advertising. An open communication platform can enhance the readers' loyalty, fully triggering the target readers' value. Thus, enterprises can meet more personalized needs and obtain greater benefits.

\subsection{Grasp the Pay-for-Knowledge Economy and Create A New Profit Model}

The pay-for-knowledge economy is the product of the market economy, which reflects the market value of product. Paying for knowledge is perfectly justified. For the editing industry, it means significant values and business prospect for the editing industry. At present, many publishers are trying to launch their own chargeable electronic publication, thus achieving the "gain returns from electronic contents". As the owner of the copyright, the publishing house should take advantage of the dividends brought by the "pay-for-knowledge" economy, and leverage the development of this field. The publishing house should give full play to the advantages of the author resources and contents, carry out secondary development and processing of the products, and realize the stratification and chaining of the publishing field. Different products are launched for users of different cultural levels. Therefore, users can be more accurately served. By meeting the reading needs of users, the publishing house can realize the commercial interests.

\subsection{Use Modern Digital Technology to Achieve Intelligence}

The subversive and revolutionary nature of the Internet is all-around. In the Internet era, people can break through the traditional geographical and time constraints and enjoy the Internet dividend freely. For the editing and publishing industry, we must firmly grasp the market changes brought about by digital technology, and strive to realize the intelligence of products and service. Specifically, the first is for the editing and publishing departments to achieve cross-border development. The decentralization makes the editorial publishing house slowly lose the monopoly of knowledge in the traditional sense. The cross-border development may be a trend and a change for the editing and publishing industry. We must constantly broaden the field, continue to improve the editing and publishing industry, and realize the intelligent and virtualized publication. The second is to establish an interactive and personalized platform. The editing and publishing is not limited to the traditional paper form any more. On the basis of the platform, we can achieve an interactive and personalized development. And the precise promotion can meet readers' reading needs, achieving the transformation from mechanization to intelligence.

\section{Conclusion}

Under the "Internet +" horizon, the editing and publishing have undergone tremendous changes in terms of product content and service methods. In the new era, the editing and publishing industry should pay attention to the application of Internet and information technology, and make best use of their own advantages of knowledge resources to achieve the intelligent development and digitalization, thus continue to meet the different needs of readers, improve the reader experience, and strive to realize the transformational development.

\section{References}

[1]. Tao, Kan. The new normal state and change path of editing and publishing industry under the "Internet +" horizon [J]. Publishing Research, 2016 (3).

[2]. Zhu, Ying. Analysis on the development path of editing and publishing industry in digital age [J]. Journal of News Research, 2017(6). 